\title{
Slow-release RGD-peptide hydrogel monoliths
}

Article

Accepted Version

Castelletto, V., Hamley, I. W., Stain, C. and Connon, C. (2012) Slow-release RGD-peptide hydrogel monoliths. Langmuir, 28 (34). pp. 12575-12580. ISSN 0743-7463 doi: https://doi.org/10.1021/la302071e Available at https://centaur.reading.ac.uk/29274/

It is advisable to refer to the publisher's version if you intend to cite from the work. See Guidance on citing.

To link to this article DOI: http://dx.doi.org/10.1021/la302071e

Publisher: American Chemical Society

All outputs in CentAUR are protected by Intellectual Property Rights law, including copyright law. Copyright and IPR is retained by the creators or other copyright holders. Terms and conditions for use of this material are defined in the End User Agreement.

\section{www.reading.ac.uk/centaur}

\section{CentAUR}

Central Archive at the University of Reading

Reading's research outputs online 


\section{Slow Release RGD-Peptide Hydrogel Monoliths}

Valeria Castelletto, ${ }^{* a}$ Ian W. Hamley, ${ }^{a}$ Christopher Stain $^{b}$ and Che Connon ${ }^{a}$

${ }^{a}$ School of Chemistry, Food Science and Pharmacy, University of Reading,

Whiteknights, Reading RG6 6AD, UK

${ }^{b}$ Centre for Advanced Microscopy, University of Reading, Whiteknights Reading, RG6 6AF, UK

*Author for correspondence e-mail: V.Castelletto@reading.ac.uk 


\section{Abstract}

We report on the formation of hydrogel monoliths formed by functionalized peptide Fmoc-RGD [Fmoc: fluorenylmethoxycarbonyl] containing the RGD cell adhesion tripeptide motif. The monolith is stable in water for nearly 40 days. The gel monoliths have a self-supporting porous structure consisting of a network of peptide fibers. The RGD-decorated peptide fibers have a $\beta$-sheet secondary structure. We prove that Fmoc-RGD monoliths can be used to release and encapsulate material, including model hydrophilic dyes and drug compounds. We give a first insight into the correlation between absorption and release kinetics of this new material, and show that both processes take place over similar time scales. 


\section{Introduction}

There is currently intense interest in the development of peptide-based hydrogels for applications in regenerative medicine/tissue engineering ${ }^{1-12}$ and the release of drugs and other actives. ${ }^{13-18}$ The peptide hydrogel as a minimum requirement must be cytocompatible, although many other elements are required to fully realise an artificial extracellular matrix (ECM). ${ }^{7,19}$ A common motif incorporated into peptide-based hydrogels is the Arg-Gly-Asp (RGD) tripeptide cell adhesion motif from fibronectin, which binds to integrins (cell-surface receptors) and is widely used to encourage cell growth in synthetic biomaterials. ${ }^{20-25}$ Here, we report on an RGDbased peptide hydrogel that can be used for slow release of hydrophilic compounds, illustrated with a model amyloid-binding dye and model hydrophilic dyes and drug compounds. The slow release concept could potentially be extended to other encapsulated hydrophilic molecules for use in slow release delivery systems or reengineering of ECM mimics.

Previous works in the literature explored the gelation of fluorenylmethoxycarbonyl (Fmoc)-RGD. The first attempt on this subject was undertaken by Gazit and co-workers, ${ }^{26}$ who initially dissolved Fmoc-RGD in dimethyl sulfoxide and then diluted in water to the final concentration, only achieving a clear solution. Shortly afterwards, Ulijn and co-workers have shown that Fmoc RGD can form a transparent hydrogel at low $\mathrm{pH}$ and peptide concentration. ${ }^{5}$

In a previous work $^{24}$ we reported on preparation of Fmoc-RGD peptide hydrogels for cell culturing. The Fmoc unit was used to control self-assembly in water, via aromatic stacking interactions. It was found that Fmoc-RGD forms well defined amyloid fibrils with a $\beta$-sheet structure for 2 wt $\%$ peptide. In addition, 2 wt $\%$ Fmoc-RGD forms self-supporting hydrogels.

Here, we investigate the formation of hydrogels in more concentrated solutions of Fmoc-RGD. This study is driven by the unusual mechanical properties of the 10 wt\% peptide gel. We found that it is possible to make monoliths of $10 \mathrm{wt} \%$ Fmoc- 
RGD hydrogel, which are stable when immersed in water for at least $\sim 40$ days. This property could find applications in the slow release of encapsulated materials. The structure of 10 wt\% Fmoc-RGD hydrogel is examined by X-ray diffraction (XRD), small angle scattering (SAXS), cryo-scanning electron microscopy (cryo-SEM) and laser scanning confocal microscopy (LSCM). We investigate the uptake and release properties of Fmoc-RGD monoliths through fluorescence spectroscopy and UV-vis absorption experiments.

\section{Experimental Section}

Materials. Fmoc-RGD was purchased from CS Bio (Menlo Park, CA) as a TFA salt. Purity is $98.89 \%$ based on HPLC using TFA in water/acetonitrile gradient, $M_{w}$ expected 568.59, found 568.87. Thioflavin T (ThT), methylene blue, salicylic acid and riboflavin were purchased from Sigma Aldrich (UK).

Hydrogel Formation. Weighed amounts of Fmoc-RGD and water were added in a vial to obtain a $10 \mathrm{wt} \%$ peptide suspension. The $\mathrm{pH}$ of the water used in this work was $\mathrm{pH}$ 6.94. $10 \mathrm{wt} \%$ Fmoc-RGD monoliths were obtained according to the two following alternative procedures:

i) The mixture was ultrasonicated for 15 minutes at $50{ }^{\circ} \mathrm{C}$. The solution was stored at $5{ }^{\circ} \mathrm{C}$ for $15 \mathrm{hrs}$, and then placed again in an ultrasonic bath at $50{ }^{\circ} \mathrm{C}$ for 10 minutes. The cooling-heating/ultrasound process was repeated for 5 days, until the sample became a homogeneous gel.

ii) The mixture was ultrasonicated for 15 minutes at $50{ }^{\circ} \mathrm{C}$. The solution was stored at $5{ }^{\circ} \mathrm{C}$ for $15 \mathrm{hrs}$. Then, the initial clustering of peptide was fragmented with a sterile needle and mixed with the excess of water in the sample using a magnetic stirrer. The mixture was finally allowed to gel at $5{ }^{\circ} \mathrm{C}$ for 2 days, in order to achieve homogeneity.

Congo Red Staining and Birefringence Monitored by Polarized Optical Microscopy (POM). A 0.5 wt\% Congo red solution was filtered and then pipetted 
onto a glass microscope slide. The peptide gel was placed under the surface of the Congo red solution and stained for approximately 2 min. The excess Congo red solution was then removed by blotting. Images of the sample placed between crossed polarisers were obtained with an Olympus CX-41 microscope.

Cryo-Scanning Electron Microscopy (cryo-SEM). Imaging was performed using an FEI Quanta 600F instrument. The peptide gel was mounted onto aluminium stubs and frozen in liquid nitrogen slush at approximately $-210^{\circ} \mathrm{C}$. Once frozen, the sample was transferred under vacuum to a sample preparation chamber and allowed to equilibrate to the appropriate temperature prior to fracturing. The gel was fractured at $-140{ }^{\circ} \mathrm{C}$ and allowed to sublime at $-90^{\circ} \mathrm{C}$ for approximately 5 minutes before an initial examination by SEM. Following this a further 5 minutes of sublimation was used to reveal more detail of the sample surface. The sample was allowed to cool at $-140{ }^{\circ} \mathrm{C}$, and then coated with platinum prior to the final imaging at $5 \mathrm{kV}$.

X-ray Diffraction (XRD). A stalk, dried from a 10 wt\% Fmoc-RGD gel, was prepared for XRD experiments. The stalk was mounted vertically onto the four axis goniometer of a RAXIS IV++ X-ray diffractometer (Rigaku) equipped with a rotating anode generator. The XRD data was collected using a Saturn 992 CCD camera.

Small-Angle X-ray Scattering (SAXS). SAXS was performed using a Bruker Nanostar instrument using $\mathrm{CuK}_{\alpha}$ radiation from an Incoatec microfocus source. The sample was sandwiched between two mica windows with a $1 \mathrm{~mm}$ thick Teflon spacer. The sample-detector distance was $65 \mathrm{~cm}$ and a Vantec-2000 photon counting detector was used to collect SAXS patterns.

Laser Scanning Confocal Microscopy (LCSM). Experiments were performed using a Leica TCS SP2 confocal system mounted on a Leica DM-IRE2 upright microscope, using an objective x63 in a glycerol-immersion lens. A 10 wt\% Fmoc-RGD gel was dyed using a $3.4 \times 10^{-3}$ wt $\%$ ThT solution, instead of pure water, as a solvent. The sample was studied using $458 \mathrm{~nm}$ excitation wavelength (Argon laser emission), together with a $463-568 \mathrm{~nm}$ emission detection range. 
Fluorescence Spectroscopy. Spectra were recorded on a Varian Cary Eclipse Fluorescence Spectrometer with samples in $10 \mathrm{~mm}$ quartz cuvette. ThT emission fluorescence was measured for $\lambda=(460-650) \mathrm{nm}$ using $\lambda_{\mathrm{ex}}=440 \mathrm{~nm}$, while the fluorenyl emission fluorescence was measured for $\lambda=(290-470) \mathrm{nm}$ using $\lambda_{\mathrm{ex}}=265$ $\mathrm{nm}$.

UV-vis Absorption. Spectra were recorded using a Varian Cary 300 Bio UV/Vis spectrometer. Samples were analyzed in quartz cuvettes with a $5.0 \mathrm{~mm}$ path length and were baseline corrected with respect to a blank cell with the appropriate solvent.

Release of Fmoc-RGD monolith studied by ThT fluorescence. A quantity of 0.1 $\mathrm{ml}$ of $10 \mathrm{wt} \%$ Fmoc-RGD hydrogel was loaded with ThT by using $9.8 \times 10^{-3}$ wt $\%$ ThT as a solvent. The monolith was then immersed in $1.5 \mathrm{ml}$ of water. The fluorescence emission of the liquid surrounding the peptide monolith was measured as a function of time $\left(\lambda_{\mathrm{ex}}=440 \mathrm{~nm}\right)$.

Release of Fmoc-peptide monomers from peptide monoliths studied by fluorescence. $0.1 \mathrm{ml}$ of $10 \mathrm{wt} \%$ Fmoc-RGD monolith was prepared using water as a solvent, and then immersed in $1.5 \mathrm{ml}$ of water. The fluorescence emission of small fractions of liquid surrounding the peptide monolith $(0.01 \mathrm{ml}$ diluted by 325 -fold in water) was measured at regular intervals of time $\left(\lambda_{\mathrm{ex}}=265 \mathrm{~nm}\right)$.

Release and uptake of methylene blue by Fmoc-RGD monoliths studied by UVvis spectroscopy. Fmoc-RGD gel dye uptake was measured by immersing $0.1 \mathrm{ml}$ of 10 wt $\%$ Fmoc-RGD hydrogel into $3 \mathrm{ml}$ of $4.9 \times 10^{-4}$ wt $\%$ methylene blue. In order to measure the release of dye by the hydrogel, we prepared $0.1 \mathrm{ml}$ of $10 \mathrm{wt} \%$ FmocRGD hydrogel loaded with methylene blue by using a $5.6 \times 10^{-3} \mathrm{wt} \%$ methylene blue solution as a solvent. The hydrogel was then immersed in $3 \mathrm{ml}$ of water. The UV-vis spectra of the solution surrounding the hydrogel were measured at regular interval of times, in order to evaluate both uptake and release of methylene blue by Fmoc-RGD monoliths. 


\section{Results and Discussion}

Weighed quantities of Fmoc-RGD and water were mixed, inside a $0.5 \mathrm{ml}$ Eppendorf, to a $10 \mathrm{wt} \%$ peptide concentration. The resulting gel surprisingly adopted a rigid structure, moulded by the Eppendorf tube, allowing for the preparation of a gel monolith similar to that displayed in Figure 1a.

The birefringence of the sample was studied by polarized optical microscopy and Congo red staining experiments. The latter assay is used to identify amyloid selfassembly, since uptake of Congo red leads to characteristic birefringence. ${ }^{27}$ The texture obtained for the gel (Figure S1, Supplementary Information) suggests the formation of amyloid fibrils. This result was confirmed by the blue-green birefringence resulting from Congo red staining, shown in the inset of Figure S1.

Small angle X-ray scattering (SAXS) experiments were used as an in situ method to examine the self-assembled nanoscale structure. The SAXS intensity $I(q)$ measured for 10 wt\% Fmoc-RGD was fitted using Porod's approximation for a long infinite cylinder, with a Gaussian size distribution to account for the polydispersity in cylinder radius (Figure 2). The fitting of the SAXS data in Figure 2 is not highly accurate at low scattering angles because our model does not consider interactions between the peptide fibrils (present at high concentrations) ${ }^{28}$ but only the shape of the peptide fibrils. However, the SAXS fitting in Figure 2 corresponds to a radius $R=$ $(35 \pm 5) \AA$, in good agreement with the cylinder radius $(40 \pm 18) \AA$ previously found by us for 2 wt $\%$ Fmoc-RGD. ${ }^{24}$ The estimated extended peptide length of $17 \AA$ $([3 \times 3.5+6] \AA=16.5 \AA$ where $3.5 \AA$ is the repeat distance $\beta$-strand and $6 \AA$ is the estimated size of the Fmoc unit), compared to the fibril radius provided by SAXS in Figure 2, suggests that each Fmoc-RGD fibril is up to 4 extended Fmoc-RGD molecules in width.

The SAXS fitting in Figure 2 corresponds to a cylinder $300 \AA$ long, shorter than the $800 \AA$ I long peptide fibrils previously measured by us for 2 wt\% Fmoc-RGD from 
the modelling of the SAXS data. ${ }^{24}$ The wide difference in peptide length between 2 and $10 \mathrm{wt} \%$ peptide, reflects partly the high polydispersity in that structural parameter and also the lack of sensitivity of the fit to this parameter in the limit that the length $L$ $>R$.

Cryo-SEM was used to image the self-assembled structure of the $10 \mathrm{wt} \%$ Fmoc-RGD gel. A representative image is shown in Figure S2 (Supplementary Information). The gel structure consists of a network of fibres, assembled to form a porous structure with a highly polydisperse pore size of $(247 \pm 100) \mathrm{nm}$ (Figure S2a). The fibres comprising the network are $(61.5 \pm 23.1) \mathrm{nm}$ thick (Figure S2b). Some clustering of fibres was observed, which may be the origin of the cloudiness observed for the hydrogel (Figure 1a). It is highly probable that the fibres in Figure S2b correspond to bundles of the $35 \AA$ radius fibrils revealed by SAXS.

XRD was performed on a $10 \mathrm{wt} \%$ Fmoc RGD gel and on a stalk dried from such a gel. The 2D spectra revealed a partial orientation of the crystallographic planes (Figure S3, Supplementary Information). The meridional reflection at $4.71 \AA$ (Figure S3) corresponds to the in-plane spacing of a $\beta$-sheet. ${ }^{27}$ The equatorial reflections measured for the stalk (Figure S3), are associated to the lateral ordering of $\beta$-sheet strands. ${ }^{27}$

Fmoc-RGD monoliths have $\mathrm{pH}$ 2. Our results show that when $0.1 \mathrm{ml}$ of $10 \mathrm{wt} \%$ Fmoc-RGD is immersed in $3 \mathrm{ml}$ of water, the initial $\mathrm{pH}$ of the water $(\mathrm{pH} \mathrm{6.94)}$ decreases to 3.86 after one minute, and remains stable with an average value of $(3.47 \pm 0.14)$ for the next two days. As a consequence of the acidic properties of the gel and the solution surrounding it, Fmoc-RGD monoliths might find applications as topical agents for encapsulation of drugs used in skin therapeutics.

The properties of Fmoc-RGD hydrogel as a slow release encapsulating agent were investigated. In particular, we qualitatively evaluated the interplay between the release and absorption properties of the hydrogel. 
We prepared a $10 \mathrm{wt} \%$ Fmoc-RGD gel loaded with $3.4 \times 10^{-3} \mathrm{wt} \%$ of the amyloid-binding fluorescent probe ThT. The resulting rectangular monolith is displayed in Figure 1b. The probe ThT was loaded to enhance visual observation and to allow for fluorescence experiments described below.

In order to study the release properties of the Fmoc-RGD hydrogel, a piece of the monolith in Figure $1 \mathrm{~b}$ was immersed in water. The peptide gel initially remained stable in water (Figure 1c). By the ninth day it was possible to observe the detachment of a fibrillar structure, which continued to grow until the fortieth day (Figure 1d). Confocal microscopy was used to investigate the structure of the detached material in Figure 1d. The results, displayed in Figure 1e, show that peptide fibres detach, in a slow process, from the main body of the peptide gel. However, it is notable that after the detachment process, the initial aspect of the sample (Figure 1c) remained nearly unaltered after 40 days. It is remarkable that this gel, with no covalent cross-linking but only non-covalent supramolecular interactions, is so stable in dissolution.

The release kinetics from the concentrated Fmoc-RGD gel was studied by ThT fluorescence, ${ }^{29-30}$ following the procedure already described in the experimental section. The fluorescence emission of the solution fractions was characterized by a broad peak at $483 \mathrm{~nm}$. The release curve, displaying the time-dependence of the fluorescence emission intensity at $483 \mathrm{~nm}$, is shown in Figure 3.

It is well-known that ThT binds to amyloid peptide fibrils upon fibril self assembly, leading to an increase of ThT fluorescence emission at $480 \mathrm{~nm}\left(\lambda_{\mathrm{ex}}=440\right.$ $\mathrm{nm}){ }^{29-30}$ The release curve in Figure 3 shows that the fluorescence intensity increases with time, because the release process takes place through the detachment of $\beta$-sheet structures in the media, in agreement with the macroscopic detachment of fibres shown in Figure 1d. According to Figure 3, the release of 
material becomes noticeable after $380 \mathrm{~min}$. The release of amyloid fibrils from the hydrogel may be useful in creating novel functional amyloid-fibril materials.

We further studied the release of Fmoc-peptide monomers in the media using fluorescence spectroscopy, according to the procedure given in the experimental section. Previous studies on Fmoc-peptides solutions show that it is possible to monitor the emission of Fmoc-peptide monomers, by measuring the fluorenyl fluorescence at $\sim 313 \mathrm{~nm}\left(\lambda_{\mathrm{ex}}=265 \mathrm{~nm}\right) .{ }^{31-32} \mathrm{In}$ addition, the presence of fluorene excimers is detected by a red shift to $330 \mathrm{~nm}$ of the emission peak. ${ }^{31-32}$

In our work, the fluorescence emission of the solution aliquots was characterized by peaks at $304 \mathrm{~nm}$ and $313 \mathrm{~nm}$ (Figure S4, Supplementary Information). We plotted the time dependence of the fluorescence emission at 313 $\mathrm{nm}$, associated to peptide monomers, ${ }^{31-32}$ to construct the Fmoc-RGD monomer release curve shown in Figure 3. The time dependence of the fluorescence emission at $304 \mathrm{~nm}$ followed the same trend as that displayed for $313 \mathrm{~nm}$ (results not shown), suggesting that the fluorescence at $304 \mathrm{~nm}$ might also be associated with the Fmocunit.

The data in Figure 3 indicate that the release of Fmoc-RGD fibres is preceded by the expulsion of Fmoc-RGD monomers in the solution. Regarding drugs delivery applications, Figure 3 shows that the release of encapsulated material is $\sim 380 \mathrm{~min}$ delayed with respect to the initial release of Fmoc-peptide monomers in the media.

The ThT fluorescence data in Figure 3 probes the release of material trapped in the fibres. The release and uptake of an alternative hydrophilic compound, which presumably is not hosted inside the peptide fibres but within the hydrogel pores, has also been examined. In particular, we performed UV/vis spectroscopy experiments to determine the uptake and release of methylene blue by Fmoc-RGD monoliths. Details of these experiments are given in the Experimental section. For Fmoc-RGD solutions, the maxima in adsorption bands are present between 233 and $309 \mathrm{~nm}$ (Figure S5, Supplementary Information) far removed from that of methylene blue 
which exhibits $\lambda_{\max }=667 \mathrm{~nm}$, allowing simple determination of the dye taken up or released by the hydrogel.

Figure 4 displays the kinetics of the release and uptake experiments measured as the time dependence of the maximum in the adsorption band at $667 \mathrm{~nm}$. Figure 4 shows that the release and uptake profiles of methylene blue by an Fmoc-RGD monolith develop over similar time scales, reaching a constant value 330 minutes after both processes have started.

Additional tests were performed in order to load the bioactive riboflavin and the hydrophilic pseudo-drug salicylic acid into Fmoc-RGD monoliths. In these experiments, the drugs were loaded by preparing gel monoliths using solutions containing the drugs as a solvent. The material loading capacity $\varepsilon=100 \times$ weight of material loaded/(weight of drug loaded + weight of dry Fmoc-RGD gel) is listed in Table 1, together with the data corresponding to the monoliths loaded with ThT and methylene blue used to perform release experiments shown in Figure 3 and Figure 4.

We further studied the absorbing properties of the Fmoc-RGD gel, following a qualitative visual method already used by Liebmann and co-workers to measure the mobility of dye throughout a Fmoc-dipeptide hydrogel. ${ }^{12}$ We first prepared a gel loaded with $3.4 \times 10^{-3}$ wt\% ThT in an Eppendorf tube. Once the ThT-loaded gel was stabilized, an additional layer of 10 wt\% Fmoc-RGD gel in pure water was formed on top, by hydrating freeze dried $10 \mathrm{wt} \%$ Fmoc-RGD gel. The additional peptide in water layer bound to the previously formed ThT-loaded hydrogel. One day after the ThTfree gel layer was stabilized, the two-layer hydrogel was removed from the Eppendorf mould. The resulting monolith is shown in Figure 5.

Figure 5 clearly shows a diffusion of dye from the ThT-loaded top towards the ThT-free base of the gel monolith. The shape of the monolith was maintained during the diffusion process, as a consequence of the rigid hydrogel structure. Since ThT is hosted within the core of the amyloid fibre, the diffusion within the gel points to the 
porous structure displayed in Figure S2a, allowing local mobility of ThT molecules within the fibrillar network.

The results in Figure 1 and Figures 3-4, suggest that absorption and release processes might co-exist in a dynamic equilibrium in the Fmoc-RGD gel. It is possible that using Fmoc-RGD gel as a delivery agent in vivo, absorption of the physiological media will not screen the slow release of the encapsulated material.

\section{Conclusions}

In summary, this report shows that concentrated gels of Fmoc-RGD offer new opportunities for developing delivery agents. The unusual rigid structure of $10 \mathrm{wt} \%$ Fmoc-RGD gel allows for the construction of peptide-based monoliths able to remain stable in water for nearly 40 days, only partially affected by the detachment of peptide fibers. We found that the structure of Fmoc-RGD monoliths consists of a network of fibers, such that each fiber is made out of a bundle of thinner fibrils with an internal $\beta$-sheet structure. Fmoc-RGD fibres build a self-supporting but porous structure in a hydrogel functionalized with RGD motifs at high density.

The RGD sequence incorporated within the hydrogel provides biocompatibility via the integrin cell adhesion motif (it does not have a particular role in drug encapsulation) whereas the fibrillar structure of the monolith enables encapsulation and release. In particular, encapsulation can be achieved by loading the material in the gel (using a solution of the material as the solvent for Fmoc-RGD gel) or alternatively through the spontaneous uptake by the Fmoc-RGD gel of the material diluted in a surrounding liquid media.

Our findings represent a new approach to the use of the Fmoc-RGD peptide amphiphile as a delivery agent, ${ }^{33-34}$ and provide a first insight into a reliable correlation between absorption and slow release properties of this material. 
Acknowledgements. This work was supported by BBSRC grant BB/I008187/1.

Supporting Information available. This information is available free of charge via the Internet at http://pubs.acs.org/. 
Table 1. Materials loaded in $0.1 \mathrm{ml}$ of $10 \mathrm{wt} \%$ Fmoc-RGD monoliths

\begin{tabular}{|l|l|l|}
\hline Materials & $\begin{array}{l}\text { Material loading capacity } \\
(\%)\end{array}$ & $\begin{array}{l}\text { Solution used as solvent to prepare } \\
\text { Fmoc-RGD monoliths }\end{array}$ \\
\hline ThT & 0.1 & $9.8 \times 10^{-3} \mathrm{wt} \%$ ThT \\
\hline Riboflavin & 0.01 & $1.27 \times 10^{-3} \mathrm{wt} \%$ riboflavin \\
\hline Salicylic acid & 0.03 & $3.5 \times 10^{-3} \mathrm{wt} \%$ salicylic acid \\
\hline Methylene blue & 0.06 & $5.6 \times 10^{-3} \mathrm{wt} \%$ methylene blue \\
\hline
\end{tabular}




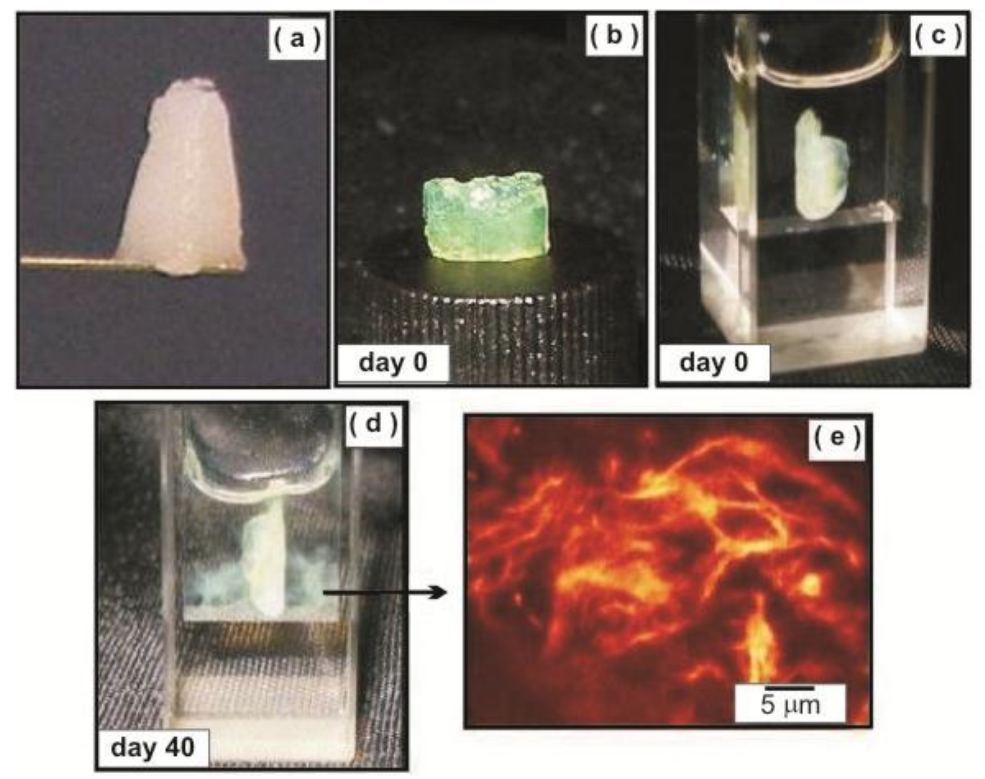

Figure 1. (a) 10 wt\% Fmoc-RGD monolith gel prepared using an eppendorf mould. (b) 10 wt\% Fmoc-RGD monolith stained with ThT. Material in (b) immersed in water at (c) day 0 and (d) day 40. (e) Laser scanning confocal microscopy image of detached material in (d). 


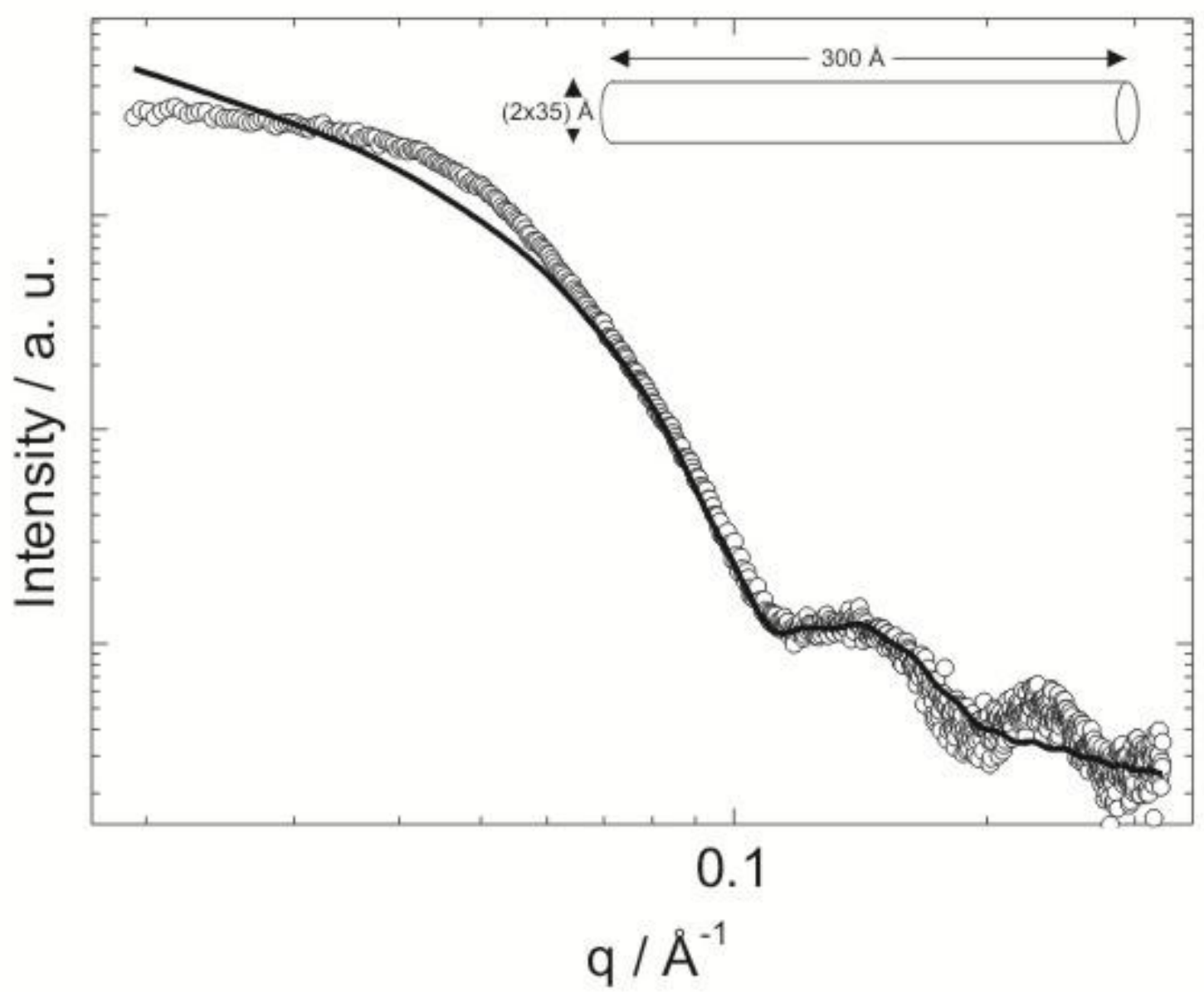

Figure 2. SAXS data for $10 \mathrm{wt} \%$ Fmoc-RGD gel. The solid line is a fit to the form factor of a long cylinder, model shown. 


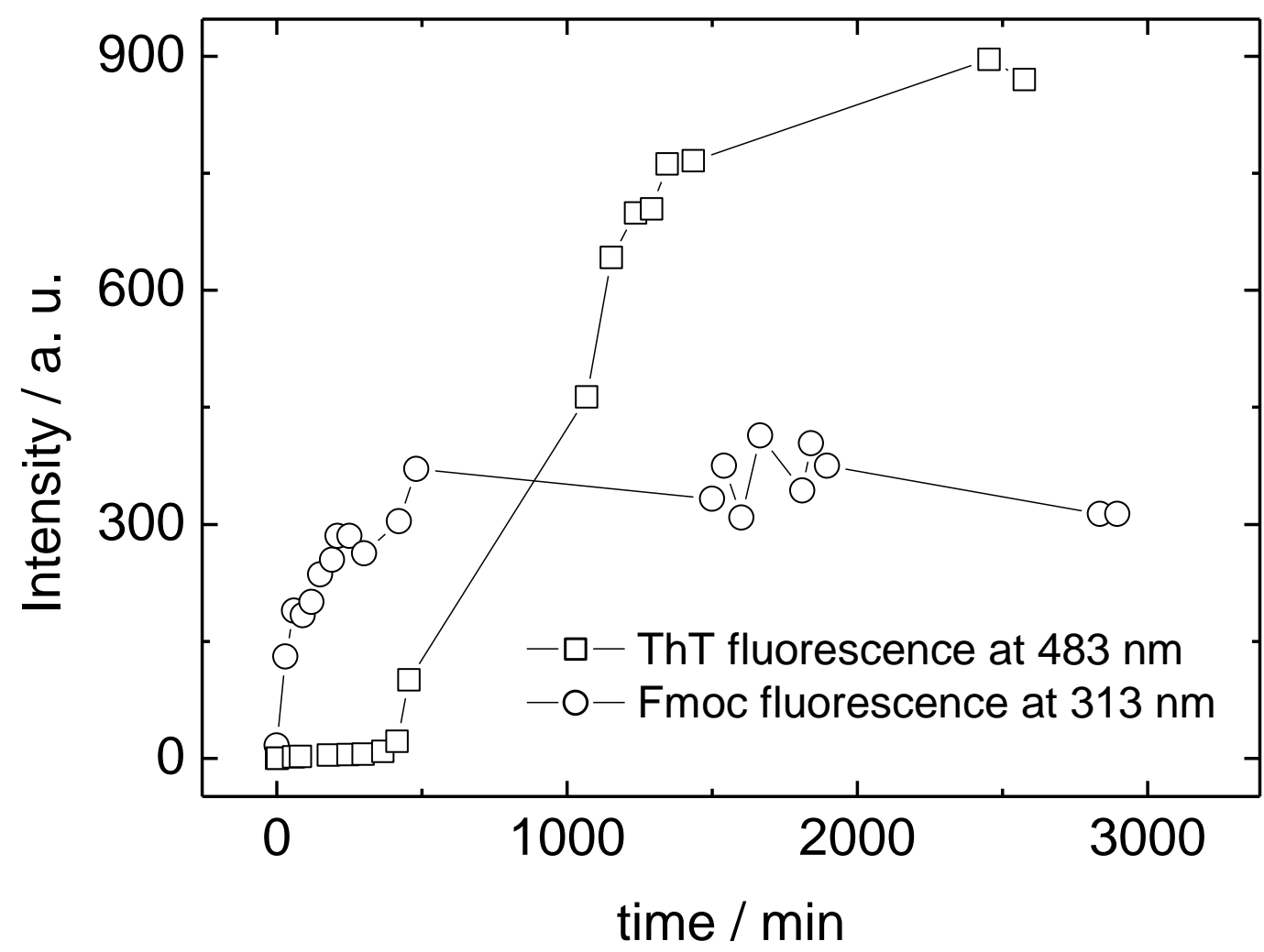

Figure 3. Fluorescence intensity showing fluorescence of ThT bound to fibrils and of Fmoc units in the Fmoc-peptides, obtained for a Fmoc-RGD monolith immersed in water. 


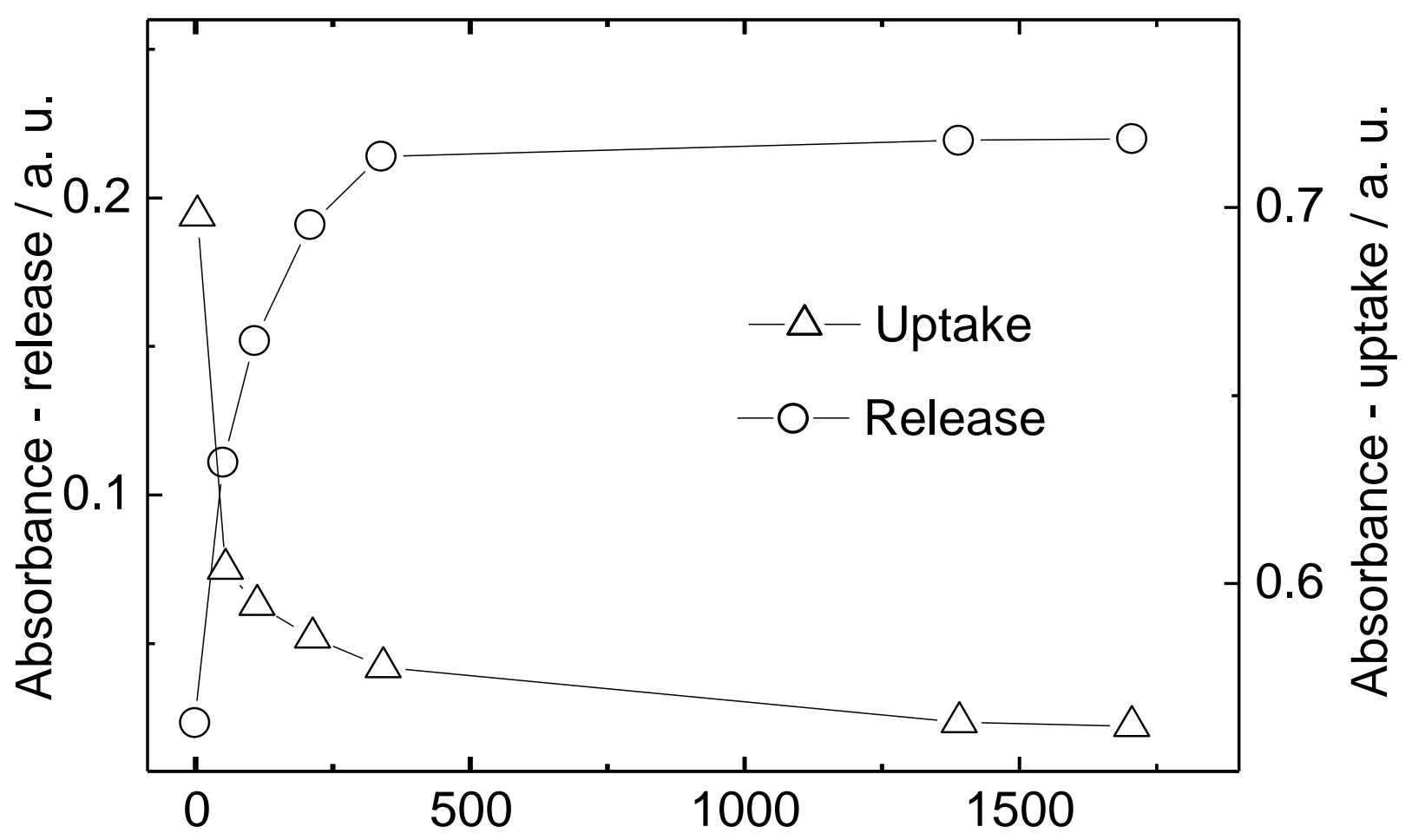

time / $\mathrm{min}$

Figure 4. Release and uptake experiments of methylene blue by a $10 \mathrm{wt} \%$ FmocRGD monolith, measured as the time dependence of the absorbance maximum at $667 \mathrm{~nm}$. 


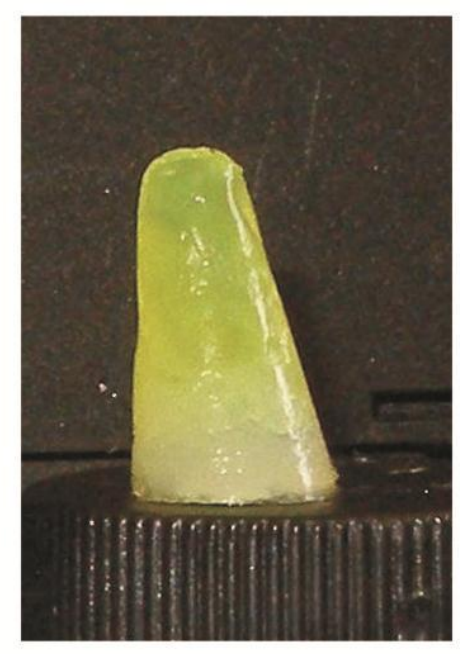

Figure 5. Fmoc-RGD monolith showing ThT diffusion through the gel. 


\section{References}

(1) Lutolf, M. P.;Hubbell, J. A. Synthetic biomaterials as instructive extracellular microenvironments for morphogenesis in tissue engineering. Nat. Biotechnol. 2005, 23, 47-55.

(2) Yang, Z.;Xu, B. Using enzymes to control molecular hydrogelation. Adv. Mat. 2006, 18, 3043-3046.

(3) Yang, Z.;Xu, B. A simple visual assay based on small molecule hydrogels for detecting inhibitors of enzymes. Chem. Comm. 2004, 2424-2425.

(4) Thornton, P. D.;Mart, R. J.;Ulijn, R. V. Enzyme-responsive polymer hydrogel particles for controlled release. Adv. Mat. 2007, 19, 1252-+.

(5) Zhou, M.;Smith, A. M.;Das, A. K.;N.W., H.;Collins, R. F.;Ulijn, R. V.;Gough, J. E. Self-assembled peptide-based hydrogels as scaffolds for anchorage-dependent cells. Biomaterials 2009, 30, 2523-2530.

(6) Haines-Butterick, L.;Rajagopal, K.;Branco, M.;Salick, D.;Rughani, R.;Pilarz, M.;Lamm, M. S.;Pochan, D. J.;Schneider, J. P. Controlling hydrogelation kinetics by peptide design for three-dimensional encapsulation and injectable delivery of cells. PNAS 2007, 104, 7791-7796.

(7) Place, E. S.;Evans, N. D.;Stevens, M. M. Complexity in biomaterials for tissue engineering. Nature Mater. 2009, 8, 457-470.

(8) Patrick, A. G.;Ulijn, R. V. Hydrogels for the Detection and Management of Protease Levels. Macromol. Biosci. 2010, 10, 1184-1193.

(9) Li, H.;Ma, Y.;Chen, Y.;Sang, X.;Zhou, T.;Qiu, M.;Huang, X.;Zhou, C.;Su, Z. A. Protease-Based Strategy for the Controlled Release of Therapeutic Peptides. Angew. Chem. Int. Ed. 2010, 49, 4930-4933.

(10) Webber, M. J.;Tongers, J.;Renault, M.-A.;Roncalli, J. G.;Losordo, D. W.;Stupp, S. I. Development of bioactive peptide amphiphiles for therapeutic cell delivery. Acta Biomater. 2010, 6, 3-11.

(11) Matson, J. B.;Zha, R. H.;Stupp, S. I. Peptide self-assembly for crafting functional 
biological materials. Curr. Opin. Solid St. M. 2011, 15, 225-235.

(12) Liebmann, T.;Rydholm, S.;Akpe, V.;Brismar, H. Self-assembling Fmoc dipeptide hydrogel for in situ 3D cell culturing. BMC Biotechnology 2007, 7, 88-99.

(13) Adams, D. J. Dipeptide and Tripeptide Conjugates as Low-Molecular-Weight Hydrogelators Macromol. Biosci. 2011, 11, 160-173.

(14) Nochi, T.;Yuki, Y.;Takahashi, H.;Sawada, S.;Mejima, M.;Kohda, T.;Harada, N.;Kong, I. G.;Sato, A.;Kataoka, N.;Tokuhara, D.;Kurokawa, S.;Takahashi, Y.;Tsukada, H.;Kozaki, S.;Akiyoshi, K.;Kiyono, H. Nat. Mater. 2010, 9, 572.

(15) Nochi, T.;Yuki, Y.;Takahashi, H.;Sawada, S. I.;Mejima, M.;Kohda, T.;Harada, N.;Kong, I. G.;Sato, A.;Kataoka, N.;Tokuhara, D.;Kurokawa, S.;Takahashi, Y.;Tsukada, H.;Kozaki, S.;Akiyoshi, K.;Kiyono, H. Nanogel antigenic protein-delivery system for adjuvant-free intranasal vaccines. Nat. Mater. 2010, 9, 685-685.

(16) Ikeda, M.;Tanida, T.;Yoshii, T.;Hamachi, I. Rational Molecular Design of Stimulus-Responsive Supramolecular Hydrogels Based on Dipeptides. Adv. Mat. 2011, 23, 2819+-.

(17) Altunbas, A.;Lee, S. J.;Rajasekaran, S. A.;Schneider, J. P.;Pochan, D. J. Encapsulation of curcumin in self-assembling peptide hydrogels as injectable drug delivery vehicles. Biomaterials 2011, 32, 5906-5914.

(18) Bakota, E. L.;Wang, Y.;Danesh, F. R.;Hartgerink, J. D. Injectable Multidomain Peptide Nanofiber Hydrogel as a Delivery Agent for Stem Cell Secretome. Biomacromolecules 2011, 12, 1651-1657.

(19) Place, E. S.;George, J. H.;Williams, C. K.;Stevens, M. M. Synthetic polymer scaffolds for tissue engineering. Chem. Soc. Rev. 2009, 38, 1139-1151.

(20) Hartgerink, J. D.;Beniash, E.;Stupp, S. I. Self-assembly and mineralization of peptide-amphiphile nanofibers. Science 2001, 294, 1684-1688.

(21) Hartgerink, J. D.;Beniash, E.;Stupp, S. I. Peptide-amphiphile nanofibers: a versatile scaffold for the preparation of self-assembling materials. PNAS 2002, 99, 5133-5138. 
(22) Guler, M. O.;Hsu, L.;Soukasene, S.;Harrington, D. A.;Hulvat, J. F.;Stupp, S. I. Presentation of RGDS epitopes on self-assembled nanofibers of branched peptide amphiphiles. Biomacromolecules 2006, 7, 1855-1863.

(23) Storrie, H.;Guler, M. O.;Abu-Amara, S. N.;Volberg, T.;Rao, M.;Geiger, B.;Stupp, S. I. Supramolecular crafting of cell adhesion. Biomaterials 2007, 28, 4608-4618. (24) Cheng, G.;Castelletto, V.;Jones, R.;Connon, C. J.;Hamley, I. W. Hydrogelation of self-assembling RGD-based peptides. Soft Matter 2011, 7, 1326-1333

(25) Castelletto, V.;Moulton, C. M.;Cheng, G.;Hamley , I. W.;Hicks, M. R.;Rodger, A.;López-Pérez, D. E.;Revilla-López, G.;Alemán, C. Self-assembly of Fmoctetrapeptides based on the RGDS cell adhesion motif. Soft Matter 2011, 1140511415.

(26) Orbach, R.;Adler-Abramovich, L.;Zigerson, S.;Mironi-Harpaz, I.;Seliktar, D.;Gazit, E. Self-Assembled Fmoc-Peptides as a Platform for the Formation of Nanostructures and Hydrogels. Biomacromolecules 2009, 10 2646-2651.

(27) Hamley , I. W. Peptide Fibrillisation. Angew. Chem. Int. Ed. 2007, 46, 81288147.

(28) Castelletto, V.;Hamley, I. W. Modelling Small-Angle Scattering Data from Micelles. Curr. Opin. Coll. Int. Sci. 2002, 7, 167-172.

(29) LeVine, $\mathrm{H}$. Thioflavine T interaction with synthetic Alzheimer's disease b-amyloid peptides: Detection of amyloid aggregation in solution. Protein Sci. 1993, 2, 404-410. (30) Nilsson, M. R. Techniques to study amyloid fibril formation in vitro. Methods 2004, 34, 151-160.

(31) Tang, C.;Ulijn, R. V.;Saiani, A. Effect of Glycine Substitution on FmocDiphenilalanine Self-Assembly and Gelation Properties. Langmuir 2011, 27, 1443814449.

(32) Hughes, M.;Xu, H.;Frederix, P. W. J. M.;Smith, A. M.;Hunt, N. T.;Tuttle, T.;A., K. A.;Ulijn, R. V. Biocatalytic Self-Assembly of 2D Peptide-Based Nanostructures. Soft Matter 2011, 7, 10032-10038. 
(33) Xu, X. D.;Liang, L. A.;Chen, C. S.;Lu, B.;Wang, N. L.;Jiang, F. G.;Zhang, X.

Z.;Zhuo, R. X. Peptide Hydrogel as an Intraocular Drug Delivery System for Inhibition of Postoperative Scarring Formation. ACS Appl. Mat.Inter. 2010, 2, 2663-2671.

(34) Liang, L.;Xu, X. D.;Chen, C. S.;Fang, J. H.;Jiang, F. G.;Zhang, X. Z.;Zhuo, R. X. Evaluation of the Biocompatibility of Novel Peptide Hydrogel in Rabbit Eye. J. Biom. Mater. Res.B 2010, 93B, 324-332. 


\section{Table of Contents Figure}

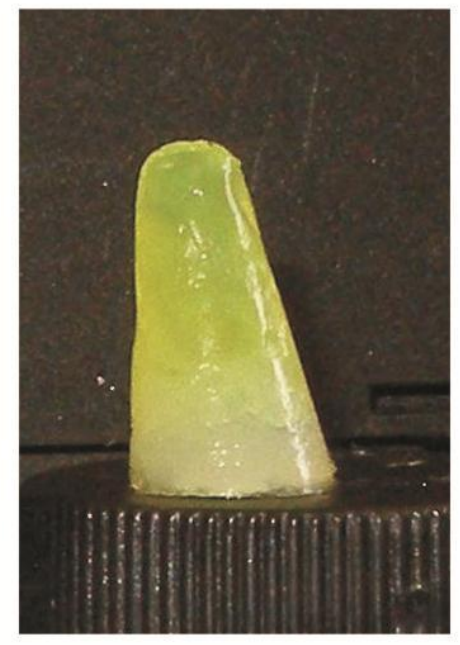

Fmoc-RGD monolith showing Thioflavin T diffusion through the gel. 